\title{
Desenvolvimento de sobremesas contemporâneas com base na diversidade brasileira
}

\section{Development of contemporary desserts based on brazilian diversity}

\author{
Fabiana Mortimer Amaral - Doutora em Química Analítica. Instituto Federal de Educação, Ciência e Tecnologia de \\ Santa Catarina (IFSC). Brasil - fabiana@ifsc.edu.br
}

Alice Nogueira Novaes Southgate - Mestra em Turismo e Hotelaria. Instituto Federal de Educação, Ciência e Tecnologia de Santa Catarina (IFSC). Brasil - alicen@ifsc.edu.br

Érika Arcaro Bez Batti - Tecnóloga em Gastronomia. Instituto Federal de Educação, Ciência e Tecnologia de Santa Catarina (IFSC).Brasil-ebezbatti@gmail.com

Palavras-chave: Sobremesas.

Contemporâneo. Frutas brasileiras. Sabores tradicionais.

\section{Keywords:}

Desserts.

Contemporary. Brazilian fruits. Traditional flavors.

\begin{abstract}
RESUMO
As produções de confeitaria podem ser um grande artifício gastronômico de valorização de saberes e fazeres tradicionais, no entanto, há pouco conhecimento sobre os doces regionais brasileiros, assim como, sobre as frutas típicas do país. O trabalho tem como objetivo o desenvolvimento de sobremesas contemporâneas, no ambiente de restauração, utilizando ingredientes que valorizem saberes culturais e a biodiversidade brasileira, através da utilização das diferentes técnicas de preparos contemporâneas. Os procedimentos metodológicos utilizados foram o Processo de Desenvolvimento de Produtos, estabelecendo critérios específicos para a elaboração das sobremesas, bem como uma revisão de literatura. Os resultados obtidos permitiram o desenvolvimento de quatro sobremesas contemporâneas denominadas “Dona Bijajica, Desconcertante, Refrescância e Manezinha”. De acordo com os resultados alcançados, conclui-se que é viável a elaboração de preparações de confeitaria que valorizem os produtos locais e técnicas tradicionais, podendo assim, transmitir os saberes e fazeres com um olhar contemporâneo.
\end{abstract}

ABSTRACT

The confectionery productions can be a great gastronomic artifice of valorization of traditional knowledge and practices, however, there is little knowledge about Brazilian regional sweets, as well as about the typical fruits of the country. The objective of this work is the development of contemporary desserts, in the restoration environment, using ingredients that value cultural knowledge and Brazilian biodiversity, through the use of different techniques of contemporary preparation. The methodological procedure applied was Product Development Process, establishing specific criteria for the preparation of desserts, as well as a literature review. The results obtained allowed the development of four contemporary desserts called "Dona Bijajica, Desconcertante, Refrescância e Manezinha". According to the results achieved, it is concluded that it is feasible to prepare confectionery preparations that value local products and traditional techniques, and can thus transmit the food culture with a contemporary look.

Como citar este artigo

AMARAL, Fabiana Mortimer; SOUTHGATE, Alice Nogueira Novaes; BATTI, Érika Arcaro Bez.Desenvolvimento de sobremesas contemporâneas com base na diversidade brasileira. Revista Brasileira de Gastronomia, Florianópolis, v. 1, n. 1, p. 34-59, jul./dez. $2018 . \quad$ Disponível em: http://rbg.sc.senac.br/index.php/gastronomia/article/view/17. Acesso em: $d d$ mm aa. 


\section{INTRODUÇÃO}

É possível perceber que a confeitaria brasileira passou por diversas influências, culturais e/ou econômicas, que formam atualmente um rico e variado acervo (FERREIRA, 2013). Devido ao modo de construção social e cultural da sociedade brasileira, caracterizado por uma mescla de conhecimentos entre os índios e diferentes imigrantes que se instalou no país, o Brasil possui uma confeitaria heterogênea.

Assim como em outras áreas da gastronomia, a confeitaria segue tendências contemporâneas com preparações mais leves, mais coloridas e atraentes. As sobremesas contemporâneas passaram a ter um aspecto visual mais alegre, formadas por uma diversidade de sabores, deixando para trás as grandes quantidades de glacê e açúcar (CUNHA et al., 2014).

Levando em consideração as características contemporâneas das sobremesas, as frutas passam a ter um papel de destaque, principalmente na forma de sorbets, trazendo frescura, contraste de temperaturas e sabores ao prato. Conforme Menegale (2004, p.58), "as frutas são a base de sobremesas há séculos - dos rincões da Babilônia às cortes francesa e italiana".

Constata-se também que as produções de confeitaria podem ser um grande artifício gastronômico de valorização de saberes e fazeres tradicionais. Em várias cidades, mais especificamente no estado de Santa Catarina, localidade onde o trabalho foi desenvolvido, observa-se uma perda considerável de conhecimentos tradicionais ligados às técnicas culinárias, visto que os hábitos alimentares estão sendo influenciados principalmente pela globalização, pelo êxodo rural, pela exploração imobiliária, entre outros.

O contexto atual da globalização tende cada vez mais a homogeneizar o conhecimento e o saber-fazer que o envolve, desaparecendo determinadas práticas que fazem parte de pequenas comunidades, conforme Müller (2012). De acordo com Krause e Bahls (2013, p.436)

atualmente, a gastronomia toma outras proporções, possuindo aspectos sociais, lúdicos, artísticos e de saúde. $O$ impacto da agricultura extensiva sobre o meio ambiente é altíssimo. Precisa-se, assim, reavaliar a maneira como se come. A gastronomia, sendo a forma mais evoluída do ser humano de relacionar-se com o seu alimento, tem o papel de aproximar a sociedade global; promover sustentabilidade por meio da produção de alimentos locais, da biodiversidade, transmitindo conhecimentos, e promovendo, consequentemente, o bemestar social.

Corroborando a esse cenário, a sustentabilidade passa a ser um fator muito utilizado e levantado por alguns movimentos da gastronomia contemporânea, como por exemplo, o Slow Food e, no Brasil, sendo esta causa praticada pelo chef Alex Atala. A gastronomia sustentável foi oficializada como conceito e prática na ONU através da resolução no 71/2016, considerando o dia 18 de junho como o dia da gastronomia sustentável, elevando a gastronomia para um nível político, servindo como instrumento de desenvolvimento econômico e social.

Assim sendo, a problemática da pesquisa que será abordada é: há a possibilidade de desenvolver sobremesas tipicamente brasileiras que valorizem a identidade cultural e os produtos regionais com técnicas e processos contemporâneos? Para atender ao questionamento, a proposta de estudo tem como base o desenvolvimento do objetivo geral e dos objetivos específicos do trabalho. 


\subsection{Objetivo geral}

Este trabalho apresenta como objetivo geral o desenvolvimento de sobremesas contemporâneas utilizando ingredientes que valorizem saberes culturais e a biodiversidade brasileira.

\subsection{Objetivos específicos}

Podemos destacar como objetivos específicos do estudo:

- incentivar a expansão da utilização de técnicas tradicionais;

- fomentar o uso de ingredientes nativos e/ou locais na confeitaria de restaurantes;

- utilizar diferentes características de movimentos da gastronomia contemporânea para o desenvolvimento de sobremesas.

\section{FUNDAMENTAÇÃO TEÓRICA}

A fundamentação teórica deste trabalho apresentará conceitos importantes para a temática abordada, utilizando autores relevantes ao assunto. Serão debatidos temas como: a história da confeitaria, a confeitaria contemporânea, a utilização e descrição de ingredientes e processos de produção contemporâneos e a diversidade brasileira com o foco nos sabores tradicionais do estado de Santa Catarina.

\subsection{História da confeitaria}

$\mathrm{O}$ ato de cozinhar merece seu lugar de destaque como uma das grandes novidades revolucionárias da história, não pela maneira como transforma a comida, mas sim, pelo modo como transformou a sociedade (CUNHA et al., 2014, ARMESTO, 2004). Nunes e Zegarra (2016, p.10) também citam que, como em toda cultura, "a culinária é uma das formas de caracterizar o estilo de vida, os hábitos e os costumes de um povo", sendo um construto da identidade cultural.

Segundo Ferreira (2013, p.34), "a confeitaria brasileira divide a sua origem entre indígena, africana escrava e portuguesa. Com influência, principalmente, destes três povos, foi constituída uma diversidade de receitas que se tornaram tradicionais brasileiras ao longo dos anos". Nesse sentido, Menegale (2004) menciona que a origem da confeitaria nacional é, antes de tudo, antropológica, histórica e elucidativa.

De acordo com Nunes e Zegarra (2016 apud MENEGALE, 2004, p.11), "os doces brasileiros têm o início de sua produção com o cultivo da cana de açúcar, a qual se deu em maior parte no Nordeste do país". Entretanto, o primeiro doce, conforme hábitos europeus, chega ao país com Pedro Álvares Cabral, em 24 de abril de 1500. Ele trazia consigo os "farféns de beira" (uma espécie de bolo recheado), os quais foram os primeiros doces de base europeias a serem degustados em território brasileiro, sendo oferecidos aos índios como presente (NUNES e ZEGARRA, 2016 apud LESNAU, 2004).

Scheliga (2016, p.23) menciona que: "com a chegada dos portugueses e dos africanos escravos, tem-se um fenômeno curioso, porque as receitas dos doces eram de origem portuguesa, mas com o uso dos ingredientes locais e executados pelas mãos das escravas africanas". Esse "fenômeno" mostra a mescla de ingredientes e técnicas que a confeitaria brasileira possui, originando uma doçaria rica em história, sabores, aromas e texturas. 
Dos portugueses, herdou-se a utilização dos ovos e do açúcar, típicos da doçaria conventual, já dos indígenas, o extenso uso da mandioca, do milho, do amendoim e das frutas, além de suas variadas produções com esses ingredientes e dos escravos africanos, as técnicas e o modo de fazer dos doces. Menegale (2004, p.54) cita que "do cultivo da cana, do engenho e da senzala, a trajetória dos doces brasileiros praticamente começa quando nasce o País".

A abundância de açúcar, na época colonial, aliada aos costumes e tradições do povo português e dos demais povos europeus que chegaram, desenvolveu o hábito do consumo de doces, que eram feitos de uma mistura de açúcar, especiarias e frutas nativas (FARIAS, 2013). Os doces brasileiros se tornaram mais doces do que em outros países, principalmente os pudins, quindins, doces de compota, de leite e de abóbora, por exemplo.

De forma geral, pouco se conhece sobre os doces regionais brasileiros e, ainda menos, sobre as frutas típicas do país. As próprias riquezas naturais são tratadas como exóticas por simples desconhecimento (SCHELIGA, 2016).

\subsection{A confeitaria contemporânea}

Antecedendo à gastronomia contemporânea, tem-se a geração de Escoffier e da nouvelle cuisine, na qual a confeitaria foi influenciada, sendo o início das sobremesas empratadas. Porém, na década de 1990, surge um novo movimento com grande repercussão devido ao trabalho do chef espanhol, Ferran Adrià. Sua abordagem é completamente diferente de tudo o que era conhecido até então, sendo extremamente inovador na aproximação ao ato de cozinhar, à criatividade na cozinha e até à forma de abordar uma refeição (SCHMITZ, 2015).

Conforme Schmitz (2015, p.5), "o trabalho de Adrià apoia-se em novas tecnologias, introduzindo também novas técnicas de suporte à criatividade na cozinha". Há uma busca de novas sensações, atribuindo importância ao sentimento aliado às preparações culinárias, sendo esse movimento chamado de gastronomia molecular.

A gastronomia molecular tem sido definida como um ramo da ciência que estuda as transformações físico-químicas de materiais comestíveis durante o cozimento e os fenômenos sensoriais associados com o seu consumo (SCHMITZ, 2014).

Observa-se o surgimento de um ramo altamente criativo da gastronomia, incentivando a inovação gastronômica através do desenvolvimento de novos produtos, equipamentos e atributos sensoriais, baseando-se no conhecimento científico (SCHMITZ, 2014). Dessa forma, de acordo com Navarro et al. (2012), a culinária baseada na ciência está intimamente associada ao design de pratos estimulantes e inovadores, que provocam nos clientes uma explosão de sensações.

O objetivo da confeitaria contemporânea é ampliar as sensações de prazer, mudar os conceitos pré-estabelecidos, enfatizar as texturas e intensificar os aromas e sabores presentes na sobremesa, onde estão envolvidos todos os sentidos, incluindo também a emoção, a diversão e o extremo deleite em degustar. Tudo isto, mexendo com os sentimentos mais profundos, buscando na memória as recordações da infância, a nostalgia e a euforia, por exemplo.

Conforme Southgate $(2015$, p.6), "a sobremesa empratada é a expressão mais original da confeitaria contemporânea e pode ser considerada uma composição de ingredientes que se combinam entre si, formando uma unidade". É também, o encerramento de uma refeição, devendo ficar gravada na memória do cliente e instigar os sentidos. 
A comida é uma das coisas que tem o poder de unir todos os sentidos, incluindo o emocional e o sensorial, conforme afirma Southgate (2015), os sentidos são a janela do corpo. Desse modo, a confeitaria contemporânea se destaca, pois consegue envolver todos os sentidos do cliente.

Uma das tendências atuais na gastronomia refere-se também à sustentabilidade. Este conceito remete-se às práticas agrícolas e do sistema alimentar que não compromete a capacidade das gerações futuras de satisfazerem as suas necessidades alimentares (SOUTHGATE, 2015). Ou seja, há um enaltecimento da sazonalidade, da regionalidade e da ligação direta com o agricultor. Além de um engrandecimento do sabor, com isso, criando-se novos estilos ao cozinhar com base em sabores sazonais, em porções menores e em diferentes formas de empratar.

\subsection{Ingredientes e processos de produção contemporâneos}

Com o advento da gastronomia molecular, a aproximação ao desenvolvimento de processos culinários deixou de ser exclusivamente empírica. A explicação científica lógica do seu mecanismo permitiu um desenvolvimento racional e mais sustentado de técnicas e processos (SCHMITZ, 2014 apud LINDEN et al., 2008). Assim sendo, surgem novos ingredientes e processos para facilitar a produção e aperfeiçoar a qualidade dos alimentos e suas preparações.

Nesse universo de inovações, os ingredientes que serão utilizados neste trabalho são os chamados hidrocolóides e, aliados a eles, os processos de vácuo e sous vide. Segundo CanellaRawls (2014, p.9), "é importante que um chef conheça os produtos com os quais lida na cozinha, sabendo como os ingredientes reagem quando misturados, quais são as particularidades de cada um e por que determinados processos físico-químicos ocorrem durante a preparação".

Os hidrocolóides podem ser obtidos de variadas matérias-primas naturais, como por exemplo, o ágar-ágar e a carragena são extraídos de algas marinhas, a pectina é extraída da casca da maçã e da laranja, a goma xantana, a goma arábica e a goma guar são derivados da celulose, ou também podem ser fabricados por processos de fermentação. Além de serem definidos como sistemas irreversíveis ou reversíveis.

A inclusão de hidrocolóides nos produtos alimentares tem inúmeras funções, tais como controle da umidade, estrutura, estabilidade e atribuição de características sensoriais vantajosas (Schmitz, 2014 apud Imenson, 2010). De acordo com Canella-Rawls (2014, p.15), "ainda que o ponto principal de um alimento seja o sabor, há de se levar em consideração também sua textura, consistência, aparência e a sensação gustativa para uma apreciação completa".

Segundo Canella-Rawls (2014, p.33),

mesmo em uma proporção tão pequena quanto $1 \%$, os hidrocolóides são capazes de produzir soluções altamente viscosas ou de formar gel em várias texturas e intensidades. Devido ao seu poder de espessamento, são usados como estabilizantes em suspensões e emulsões em que funcionam como retardadores da sedimentação de partículas.

Quanto aos novos processos utilizados, tem-se o sistema a vácuo e sous vide. De acordo com Southgate (2015, p.14), "o sous vide consiste em imergir um alimento num banho de água controlado com precisão, onde a temperatura da água é a mesma que a temperatura alvo do alimento a ser cozido". Os alimentos são colocados num saco plástico com selagem a vácuo, na qual o funcionamento do sistema de vácuo é feito por substituição mecânica do ar (MEZAROBA et 
al., 2015). Além disso, devido ao controle preciso da temperatura, há uma maior escolha sobre a textura dos alimentos do que nos métodos de cozimento tradicionais (BALDWIN, 2012).

Ao contrário do processo tradicional, no sous vide, o alimento é cozido dentro da embalagem plástica e, em consequência disto, a qualidade do sabor e os nutrientes são realçados (RAMOS, 2004). Em virtude disso, o acondicionamento a vácuo é o mais adequado para o controle correto da temperatura, sendo que há melhoria na qualidade do produto, uma vez que os aromas não podem se dispersar e o alimento fica protegido de oxidações.

\subsection{A diversidade brasileira com o foco nos sabores tradicionais do estado de Santa Catarina}

Há alguns anos, os novos chefs confeiteiros têm repensado as grandes receitas clássicas, criando novas combinações de texturas e sabores (HERMÉ, 2005). Dentro dessa perspectiva, a escolha dos sabores tradicionais do estado de Santa Catarina foi baseada nesse critério, no qual serão utilizados ingredientes tradicionais do estado para a criação de sobremesas contemporâneas.

Os ingredientes foram escolhidos conforme sua tradição no estado e definidos mediante três regiões de Santa Catarina, sendo a região de Florianópolis com o café, a mandioca com melado e o amendoim, o litoral, representado pelas cidades de Imbituba, Garopaba, Paulo Lopes e Palhoça, com a bijajica e a serra com o pinhão (conforme consta na tabela 1). Além de haver uma mescla com duas frutas típicas brasileiras: a jabuticaba e a pitanga.

\begin{tabular}{|c|c|c|c|}
\hline INGREDIENTE & HISTÓRICO & CONTRIBUIÇÃO & LOCAL \\
\hline $\begin{array}{l}\text { Aipim com } \\
\text { melado }\end{array}$ & $\begin{array}{l}\text { A mandioca mansa ou aipim era usada } \\
\text { para comer com café, com melado, nos } \\
\text { caldos de carne, nas feijoadas e até } \\
\text { assado nas brasas vivas ou borralho, } \\
\text { frita depois de cozida ou em sopas ou } \\
\text { comido com melado de cana (PEREIRA, } \\
\text { 1993). }\end{array}$ & $\begin{array}{l}\text { Indígenas/ } \\
\text { Descendentes dos } \\
\text { açorianos }\end{array}$ & $\begin{array}{l}\text { Ilha de Santa } \\
\text { Catarina } \\
\text { (Florianópolis) }\end{array}$ \\
\hline Amendoim & $\begin{array}{l}\text { Muito utilizado nas preparações, } \\
\text { principalmente associado com o aipim, } \\
\text { ambos cultivados na llha. Müller, 2012, } \\
\text { apud Várzea (1984, p. 209) relata que as } \\
\text { plantações de amendoim da região do } \\
\text { Rio Vermelho eram numerosas, sendo } \\
\text { que essas geravam uma produção } \\
\text { substancial, e que existiam também nas } \\
\text { regiões da Lagoa da Conceição e do } \\
\text { Pântano do Sul, mas que o Rio Vermelho } \\
\text { era o "empório" de amendoim da Ilha. }\end{array}$ & Indígenas & $\begin{array}{l}\text { Ilha de Santa } \\
\text { Catarina } \\
\text { (Florianópolis) }\end{array}$ \\
\hline
\end{tabular}




\begin{tabular}{|c|c|c|c|}
\hline Bijajica & $\begin{array}{l}\text { É um bolo cozido no vapor composto de } \\
\text { massa de mandioca crua, amendoim e } \\
\text { açúcar, aromatizado com erva doce, } \\
\text { cravo e canela. A preparação tem } \\
\text { origem indígena, mas a receita atual é } \\
\text { resultado da influência das famílias } \\
\text { imigrantes do século XVIII (SLOW FOOD, } \\
\text { 2017). Seu formato ganhou adaptações } \\
\text { proporcionadas pela instalação de } \\
\text { engenhos artesanais de farinha de } \\
\text { mandioca na região, onde estes } \\
\text { engenhos se multiplicaram a partir da } \\
\text { colonização dos imigrantes. }\end{array}$ & $\begin{array}{l}\text { Famílias que migraram } \\
\text { do Arquipélago dos } \\
\text { Açores }\end{array}$ & $\begin{array}{l}\text { Litoral catarinense } \\
\text { (Paulo Lopes, } \\
\text { Garopaba, Imbituba } \\
\text { e Palhoça) }\end{array}$ \\
\hline Café & $\begin{array}{l}\text { Geralmente o café era ceado com } \\
\text { garapa, que era fervida no lugar de } \\
\text { água, para adoçar o café. Isso quando } \\
\text { tiveram o café, que foi plantado um } \\
\text { pouco mais tarde (MÜLLER, 2012, apud } \\
\text { CASCAES, 1989). } \\
\text { A cultura do café teve sua produção no } \\
\text { início de } 1786 \text { na ilha de Santa Catarina, } \\
\text { atingindo no século XIX, produção } \\
\text { avultada e de excelente qualidade, } \\
\text { servindo não só ao consumo local, mas } \\
\text { também sendo exportada para o Rio da } \\
\text { Prata e para a Europa (MÜLLER, 2012, } \\
\text { apud VÁRZEA, 1984). } \\
\text { Além disso, o café era consumido com } \\
\text { farinha de mandioca (adicionando-se } \\
\text { melado, fazia-se o pirão de café), biju, } \\
\text { cuscuz, rosca de massa e, } \\
\text { acrescentando-se cachaça, tem-se a } \\
\text { consertada. }\end{array}$ & $\begin{array}{l}\text { Descendentes dos } \\
\text { açorianos }\end{array}$ & $\begin{array}{l}\text { Ilha de Santa } \\
\text { Catarina } \\
\text { (Florianópolis) }\end{array}$ \\
\hline Pinhão & $\begin{array}{l}\text { A Araucária (Araucaria angustifolia), } \\
\text { árvore nativa e símbolo da região } \\
\text { meridional do Brasil, a ponto de ser } \\
\text { chamada comumente de Pinheiro do } \\
\text { Brasil, sempre esteve na base do } \\
\text { sistema alimentar dos habitantes da } \\
\text { Serra Catarinense, tanto os humanos } \\
\text { como os animais. O pinhão representou } \\
\text { um alimento fundamental, no passar } \\
\text { dos séculos, sendo considerado um } \\
\text { "alimento de pobre", cujo valor nunca } \\
\text { foi oficialmente reconhecido em nível } \\
\text { nacional. }\end{array}$ & $\begin{array}{l}\text { Indígenas Kaingang e } \\
\text { Xokleng/Descendentes } \\
\text { colonizadores de } \\
\text { alemães e italianos }\end{array}$ & $\begin{array}{l}\text { Serra Catarinense } \\
\text { (Urubici e Lages) }\end{array}$ \\
\hline
\end{tabular}

Tabela 1. Ingredientes

Fonte: Autoras, 2017. 
Segundo Scheliga (2016, apud DÓRIA, 2016, p.17), associações históricas entre ingredientes podem perfeitamente gerar pratos modernos, equilibrados e saborosos em mãos de cozinheiros dedicados. Nessa perspectiva, Farias $(2013$, p.41) cita que "tão importante quanto inovar, é imprescindível respeitar a cultura gastronômica e a tradição alimentar de um povo".

Assim sendo, Santa Catarina é um estado onde há uma mescla de culturas e tradições devido aos seus imigrantes, refletido também na gastronomia como um todo.

Conforme Trajano (2013, p.172),

nas mesas catarinenses, o que mais se vê é o cruzamento de culturas, resultado da imigração de povos tão diversos quanto açorianos, eslavos, alemães, italianos e portugueses. Todos deixaram suas marcas na história, no idioma, nos hábitos e, não menos importante, na culinária local, que mescla de maneira harmoniosa as influências estrangeiras às técnicas e aos ingredientes já usados pelos indígenas.

A cozinha é o universo onde convivem intuição, sensibilidade, imaginação e criatividade, permitindo múltiplas dimensões e integrações. Entretanto, também um espaço de desaparecimentos, de perdas e destruições (SANTOS, 2005). Nesse sentido, alguns dos ingredientes utilizados para a produção de sobremesas contemporâneas são integrantes da Arca do Gosto, como por exemplo, a bijajica, o pinhão e a pitanga. De acordo com Slow Food (2007, online), "a Arca do Gosto é um catálogo mundial que identifica, localiza, descreve e divulga sabores quase esquecidos de produtos ameaçados de extinção, mas ainda vivos, com potenciais produtivos e comerciais".

Nesse sentido, Schiochet (2017, on-line) cita que "o resgate de plantas endêmicas do Brasil e dos costumes indígenas ainda está no início, e mesmo que a identidade brasileira na confeitaria tenha partido de memórias de outrem, temos maneiras de preparar e comer só nossas". Dessa maneira, serão utilizadas frutas típicas brasileiras e que estão em sua época de colheita (conforme consta na tabela 2), uma vez que a jabuticaba e a pitanga também são insumos pouco explorados na confeitaria.

A classificação do tipo de jabuticaba utilizada neste trabalho ocorreu conforme os saberes de Adão Baesso, proprietário de uma empresa que vende mudas de plantas em Turvo/SC e de acordo com as informações de Lorenzi (2015).

\begin{tabular}{c|l|l}
\hline \multicolumn{1}{c|}{ FRUTAS } & \multicolumn{1}{c}{ JABUTICABA } & \multicolumn{1}{c}{ PITANGA } \\
\hline Nome científico & Myrciaria coronata Mattos & Eugenia uniflora L. \\
\hline \multirow{2}{*}{ Local nativo } & $\begin{array}{l}\text { Desconhecido, uma vez que } \\
\text { nunca foi encontrada na } \\
\text { natureza, tendo sido descrita } \\
\text { em 1976 a partir de material } \\
\text { cultivado (LORENZI, 2015). }\end{array}$ & $\begin{array}{l}\text { Nativa das matas semidecíduas } \\
\text { do planalto e da bacia do Paraná } \\
\text { desde Minas Gerais até o Rio } \\
\text { Grande do Sul, bem como das } \\
\text { restingas de toda a costa } \\
\text { brasileira (LORENZI, 2015). }\end{array}$ \\
\hline \multirow{2}{*}{ Tipo de fruto } & $\begin{array}{l}\text { Frutos atropurpúreos ou negros, } \\
\text { tendo o contorno do disco, no }\end{array}$ & $\begin{array}{l}\text { Frutos globoso-costados, de } \\
\text { tamanho e cor variáveis com a }\end{array}$ \\
\hline
\end{tabular}




\begin{tabular}{l|l|l}
\hline & $\begin{array}{l}\text { ápice, de cor esbranquiçada, } \\
\text { com polpa suculenta e acidulada } \\
\text { (LORENZI, 2015). }\end{array}$ & $\begin{array}{l}\text { forma (variedade), de polpa } \\
\text { suculenta, com sabor doce ou } \\
\text { acidulado, ocasionalmente } \\
\text { resinoso (LORENZI, 2015). }\end{array}$ \\
\hline Maturação & De outubro a novembro. & De outubro a janeiro. \\
\hline Forma de cultivo de & $\begin{array}{l}\text { Cultivada em pomares } \\
\text { domésticos. }\end{array}$ & $\begin{array}{l}\text { Cultivada em pomares } \\
\text { domésticos de todo o país e } \\
\text { comercialmente no Nordeste. }\end{array}$ \\
\hline Climatério & In natura, doces e geleias. & $\begin{array}{l}\text { In natura, sucos, sorvetes, } \\
\text { geleias, licores e molhos } \\
\text { salgados. }\end{array}$ \\
\hline
\end{tabular}

Tabela 2. Frutas.

Fonte: Autoras, 2017.

\section{METODOLOGIA}

A pesquisa do presente estudo tem como finalidade ser exploratória, sendo classificada como qualitativa. Esse tipo de pesquisa tem como objetivo principal o aprimoramento de ideias através de elaboração de suposições de aplicações e sua posterior análise qualitativa do objeto foco da pesquisa. A metodologia de desenvolvimento de produtos aplicada leva em consideração a escolha de critérios para seleção dos produtos.

Para o alcance do objetivo do trabalho, em que se propõe o desenvolvimento de sobremesas contemporâneas baseada nos produtos regionais presentes na biodiversidade brasileira e dos saberes e fazeres culinários catarinenses realizou-se uma revisão de literatura e a utilização da metodologia de desenvolvimento de produtos.

O Processo de Desenvolvimento de Produtos (PDP) busca definir um conjunto de ações para analisar as necessidades do mercado, as possibilidades, as restrições tecnológicas e as estratégias competitivas, chegando às especificações de um produto e de seu processo de produção (FARIA et al., 2008). A metodologia proposta foi dividida nas seguintes fases:

Fase 0 - Avaliação de conceito: definir quais frutas e sabores tradicionais de Santa Catarina seriam abordados, técnicas e processos contemporâneos, bem como as características básicas das sobremesas.

Fase 1 - Planejamento e especificação: foram definidos os produtos, modos de apresentação em função das diferentes técnicas aplicadas, saberes e fazeres que possuam registro cultural, disponibilidade dos ingredientes conforme sazonalidade, utilização de espessantes e gelificantes na gastronomia molecular, além de determinar a viabilidade do desenvolvimento.

Fase 2 - Desenvolvimento: as sobremesas propostas foram desenvolvidas levando em consideração os critérios pré-estabelecidos na fase 1.

Fase 3 - Teste e avaliação: neste momento foi realizado o preparo e a avaliação sensorial dos produtos pela autora, tendo como objetivo verificar durante as etapas de produção as dificuldades, viabilidade de produção comercial e a aplicabilidade gastronômica. 
A maioria dos ingredientes utilizados neste trabalho foram adquiridos de pequenos produtores orgânicos do Sul de Santa Catarina ou coletados em diferentes espaços do estado, caracterizados como Bioma de Mata Atlântica e coletadas pelas autoras.

\section{RESULTADOS}

Na revisão bibliográfica foi constatada a origem da confeitaria brasileira, bem como sua contemporaneidade, a utilização de hidrocolóides e de processos de produção contemporâneos como o sous vide e o vácuo, além da descrição dos sabores tradicionais do estado de Santa Catarina e das frutas brasileiras escolhidas.

Durante o mês de novembro de 2017 foi desenvolvido nos laboratórios do Campus IFSC Florianópolis - Continente, quatro sobremesas contemporâneas tendo por base os sabores tradicionais de Santa Catarina escolhidos e duas frutas típicas brasileiras. Como base para as produções desenvolvidas foram usados critérios específicos.

Os critérios estabelecidos tiveram como base:

1 - Saberes e fazeres tradicionais de Santa Catarina com registro cultural - dois dos sabores (bijajica e pinhão) e uma das frutas (pitanga) escolhidos estão listados na Arca do Gosto, além dos outros ingredientes serem descritos em livros e trabalhos científicos como tradicionais.

De acordo com Krause e Bahls (2013, p.443),

a preservação de diversas matérias-primas e diferentes métodos de preparos é um incentivo direto à biodiversidade. Produções tradicionais fomentam a produção artesanal de alimentos, combatendo a industrialização e a massificação de nossa dieta, pois a padronização oferecida pelo fast food pode homogeneizar os alimentos a ponto de uma completa extinção de diversas espécies e aspectos culturais gastronômicos.

2 - Sazonalidade - A escolha das frutas selecionadas ocorreu devido ao tempo possível de execução da pesquisa, por haver disponibilidade de colheita e por estarem em sua época de safra. Optou-se pela utilização do pinhão no formato de paçoca, pois já é comercialmente vendido congelado, o que não acontece com as frutas, por exemplo.

Além disso, o potencial econômico de comercialização da jabuticaba é grande, em função das características sensoriais para consumo conforme Vieites et al. (2011). É uma fruta que tem despertado grande interesse entre os produtores rurais devido a sua alta produtividade, rusticidade e aproveitamento de seus frutos nas mais diversas formas. Apesar do elevado potencial de comercialização da jabuticaba, a utilização desse fruto pela indústria de alimentos é ainda escassa de acordo com Sanches et al. (2015), o que ocorre da mesma forma com a pitanga, já que sua principal forma de comercialização é através da polpa congelada (VIZZOTTO, 2006).

Krause e Bahls (2013, p.440) citam que

usar esses alimentos dentro de seu período sazonal na elaboração de cardápios oferece ao restaurador uma opção de variações de ingredientes conforme as estações climáticas. Além disso, a qualidade de uma preparação consumida dentro do seu período natural de disponibilidade dos seus ingredientes é, segundo McGee (1984), superior à daquela produzida no decorrer do ano todo. 
3 - Modo de apresentação - todas as sobremesas foram empratadas baseadas no estilo contemporâneo da confeitaria, oferecendo uma nova apresentação, principalmente, aquelas preparações consideradas tradicionais como a bijajica e a consertada.

Foram seguidos alguns critérios para o empratamento, sendo o tema principal como destaque no prato, seus componentes complementares como reduções e coulis, decorações tais como flores comestíveis, crocância, tendo como objetivo fornecer contraste de texturas e componentes adicionais como sorvete e frutas. Os ingredientes podem combinar por harmonização ou por contraste, certificando-se que exista um equilíbrio entre os componentes e não competição de sabores entre eles.

4 - Utilização de hidrocolóides e processos contemporâneos - os hidrocolóides foram selecionados de acordo com suas propriedades funcionais desejadas nos alimentos e foram priorizados os processos que contribuíram para melhorar as características sensoriais das frutas utilizadas.

Segue abaixo a descrição das técnicas utilizadas para a produção das sobremesas, bem como a percepção sensorial das mesmas.

\subsection{Sobremesa 1: "Dona Bijajica”}

A primeira sobremesa intitulada como "Dona Bijajica" consiste em: bijajica do litoral com sorvete de melado com gengibre, coulis de jabuticaba e farofa doce de pinhão, conforme consta na figura $1 \mathrm{~b}$. Os ingredientes destacados neste trabalho que foram utilizados são a bijajica, 0 melado, a jabuticaba, o pinhão e o amendoim.

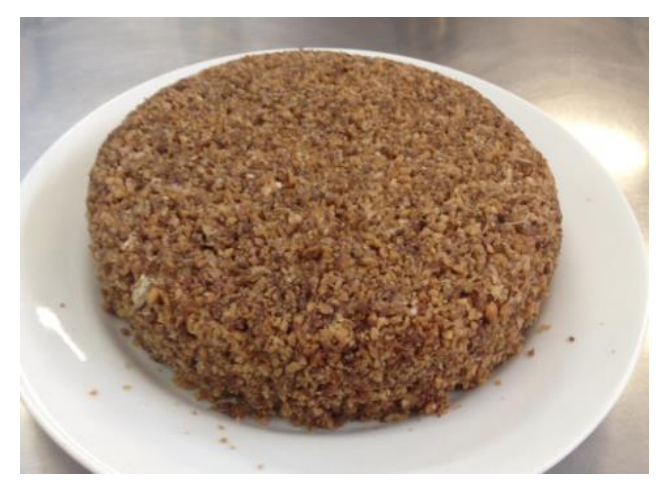

Figura 1a. Bijajica do litoral. Fonte: Autoras, 2017.

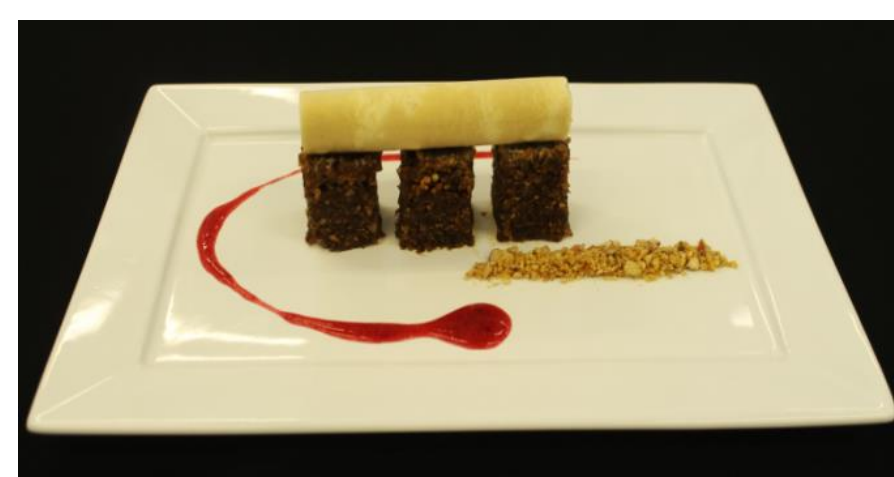

Figura 1b. Dona Bijajica. Fonte: Autoras, 2017.

A bijajica preparada neste trabalho consiste na produção típica do litoral catarinense conforme consta na figura 1a, uma vez que há outra preparação no estado de Santa Catarina com o mesmo nome, sendo que esta última é uma rosquinha de polvilho frita e muito conhecida na Serra Catarinense. $O$ intuito de utilizar a bijajica do litoral é para disseminar sua história e seu modo de preparo, em especial a valorização de processos indígenas.

A origem indígena da bijajica do litoral é revelada pelas matérias-primas essenciais que compõem sua receita: a mandioca e o amendoim, sendo que estes ingredientes eram muito utilizados pelos povos guaranis no litoral catarinense (SLOW FOOD, 2014). A contribuição europeia para a receita se dá através do molde dado à produção, das especiarias utilizadas e, provavelmente, a inclusão do açúcar. 
Seu olhar contemporâneo ocorreu através de uma nova forma de empratamento da bijajica, na qual se adicionou melado para trazer umidade ao bolo e conseguir obter o formato desejado no cortador utilizado para o empratamento. Utilizou-se também a embaladora a vácuo Selovac 200 B para a jabuticaba e, após alguns testes, para obter o resultado desejado, escolheuse o programa 3 da máquina, sendo que a mesma possui 9 programas, com 40 segundos de vácuo, tempo de selagem: 1,7 segundos e cap. da bomba Busch de vácuo: $25 \mathrm{~m}^{3} / \mathrm{h}$.

Após esse procedimento, utilizou-se o sous vide na fruta, sendo que a jabuticaba mantevese inteira após o processo, enaltecendo ainda mais o brilho, sabor e aroma da fruta. Como afirma Ramos (2004), no sistema sous vide, a água não interage quimicamente com o alimento, ou seja, os sabores e nutrientes do alimento permanecem. Além de proporcionar uma textura diferenciada ao alimento e a segurança alimentar no processo.

Por fim, empregou-se o hidrocolóide xantana no coulis de jabuticaba para obter a consistência desejada e, devido a isso, não houve a perda de nenhum atributo sensorial da fruta, em função do método de cocção contemporâneo utilizado, sous vide. Optou-se por usar 0,5\% de xantana sobre a quantidade de suco de jabuticaba obtido, uma vez que a utilização de $1 \%$ deixou o coulis muito espesso. Além disso, houve, também, o cuidado com a utilização do mixer, batendo vagarosamente para não produzir muitas bolhas de ar indesejadas.

Após todas as técnicas aplicadas e produções feitas, realizou-se a degustação da sobremesa. Constatou-se um equilíbrio entre os sabores presentes na sobremesa. A adição do melado trouxe a umidade que faltava à bijajica, a crocância estava presente no amendoim, tanto inserido no bolo como na farofa doce de pinhão, o coulis de jabuticaba e o sorvete de melado com gengibre trouxeram a refrescância precisa para complementar a sobremesa.

As fichas técnicas de produção (tabelas 3, 4, 5 e 6) demonstram os procedimentos e métodos de cocção utilizados na elaboração da sobremesa.

NOME DO PRODUTO: BIJAJICA DO LITORAL CATARINENSE

\begin{tabular}{l|l|l}
\hline \multicolumn{1}{c|}{ INGREDIENTE } & \multicolumn{1}{|c}{ QUANTIDADE } & \multicolumn{1}{c}{ UNIDADE } \\
\hline Mandioca (limpa) & 515 & $\mathrm{~g}$ \\
Amendoim vermelho cru & 390 & $\mathrm{~g}$ \\
Açúcar mascavo & 195 & $\mathrm{~g}$ \\
Sal & 1 & pitada \\
Canela em pó & 1 & pitada \\
\hline TOTAL & 1100 & $\mathrm{~g}$ \\
\hline
\end{tabular}

Modo de preparo:

1. Passe a mandioca no processador. Despeje a mandioca em um pano de algodão e esprema para retirar o líquido, fazer isso aos poucos. Reserve.

2. Passe o amendoim no processador.

3. Misture todos os ingredientes.

4. Coloque a massa, sem apertar, na parte de cima de uma cuscuzeira ou em uma panela de vapor, forrada com pano de algodão.

5. Cubra com as pontas do pano, feche a panela e cozinhe por meia hora.

6. Desenforme quando o bolo estiver morno. 
NOME DO PRODUTO: SORVETE DE MELADO COM GENGIBRE

\begin{tabular}{l|l|l}
\hline \multicolumn{1}{c|}{ INGREDIENTE } & \multicolumn{1}{|c}{ QUANTIDADE } & \multicolumn{1}{c}{ UNIDADE } \\
\hline Melado & 60 & $\mathrm{ml}$ \\
Leite & 240 & $\mathrm{ml}$ \\
Creme de leite & 60 & $\mathrm{~g}$ \\
Gengibre & 15 & $\mathrm{~g}$ \\
Glucose de milho & 20 & $\mathrm{~g}$ \\
Leite em pó & 12 & $\mathrm{~g}$ \\
Gemas & 2 & unid \\
\hline TOTAL & 447 & $\mathrm{G}$ \\
\hline
\end{tabular}

Modo de preparo:

1. Descasque o gengibre com uma colher e pique em fatias finas. Reserve.

2. Em uma panela, junte o leite e o creme de leite e leve ao fogo. Antes de levantar fervura, desligue o fogo.

3. Acrescente o gengibre ao leite aquecido e deixe em infusão por 15 minutos.

4. Coe o leite com gengibre e adicione a glucose e o melado. Leve ao fogo para a glucose derreter, mexendo de vez em quando.

5. Despeje o líquido sobre as gemas, mexendo com um fouet. Retorne ao fogo até atingir 84 ㅇ. .

6. Quando esfriar, bata no mixer e leve para a sorveteira até congelar.

Tabela 4. Produção do Sorvete de melado com gengibre.

Fonte: Autoras, 2017.

NOME DO PRODUTO: COULIS DE JABUTICABA

\begin{tabular}{l|l|l}
\hline \multicolumn{1}{c|}{ INGREDIENTE } & \multicolumn{1}{|c}{ QUANTIDADE } & \multicolumn{1}{c}{ UNIDADE } \\
\hline $\begin{array}{l}\text { Passo 1: } \\
\text { Jabuticaba in natura }\end{array}$ & 200 & $\mathrm{~g}$ \\
Licor de jabuticaba & 40 & $\mathrm{ml}$ \\
Xarope simples & 50 & $\mathrm{ml}$ \\
Passo 2: & & \\
"Suco" da jabuticaba & 80 & $\mathrm{ml}$ \\
Xantana & 0,4 & $\mathrm{~g}$ \\
\hline TOTAL & 370,4 & $\mathrm{G}$ \\
\hline
\end{tabular}


Modo de preparo:

Passo 1: 1. Coloque todos os ingredientes no saco plástico específico para usar com embaladora a vácuo.

2. Leve para a embaladora a vácuo e dê o vácuo por 40 segundos.

3. Leve para a geladeira e deixe por 24 horas.

4. Coloque a jabuticaba no sous vide a $83^{\circ} \mathrm{C}$ por 30 minutos.

5. Quando esfriar, abra o saco plástico, esprema a jabuticaba, com o auxílio de uma colher, em uma peneira. Guarde as cascas.

Passo 2: 1. Adicione a xantana no "suco" da jabuticaba extraído e bata com o mixer, aos poucos, até obter uma mistura homogênea.

\begin{tabular}{l|l|l}
\hline \multicolumn{3}{c}{ NOME DO PRODUTO: FAROFA DOCE DE PINHÃO } \\
\hline \multicolumn{1}{c|}{ INGREDIENTE } & \multicolumn{1}{c}{ QUANTIDADE } & \multicolumn{1}{c}{ UNIDADE } \\
\hline Paçoca de pinhão & 230 & $\mathrm{~g}$ \\
Amendoim & 200 & $\mathrm{~g}$ \\
Açúcar mascavo & 200 & $\mathrm{~g}$ \\
Fubá & 200 & $\mathrm{~g}$ \\
\hline \multicolumn{1}{c|}{ TOTAL } & 830 & $\mathrm{~g}$ \\
\hline
\end{tabular}

Modo de preparo:

1. Torre o amendoim no forno e retire a casca.

2. Junte todos os ingredientes e leve ao processador até a mistura ficar homogênea.

Tabela 6. Produção da Farofa doce de pinhão.

Fonte: Autoras, 2017.

\subsection{Sobremesa 2: “Desconcertante"}

A segunda sobremesa intitulada como "Desconcertante" consiste em uma farofa doce de farinha de mandioca, esferificação da consertada, melado e redução de café, conforme consta na figura 2. Os ingredientes destacados neste trabalho que foram utilizados são a mandioca (na forma de beiju quebrado), melado e o café, em seu tipo tradicional e como consertada. 


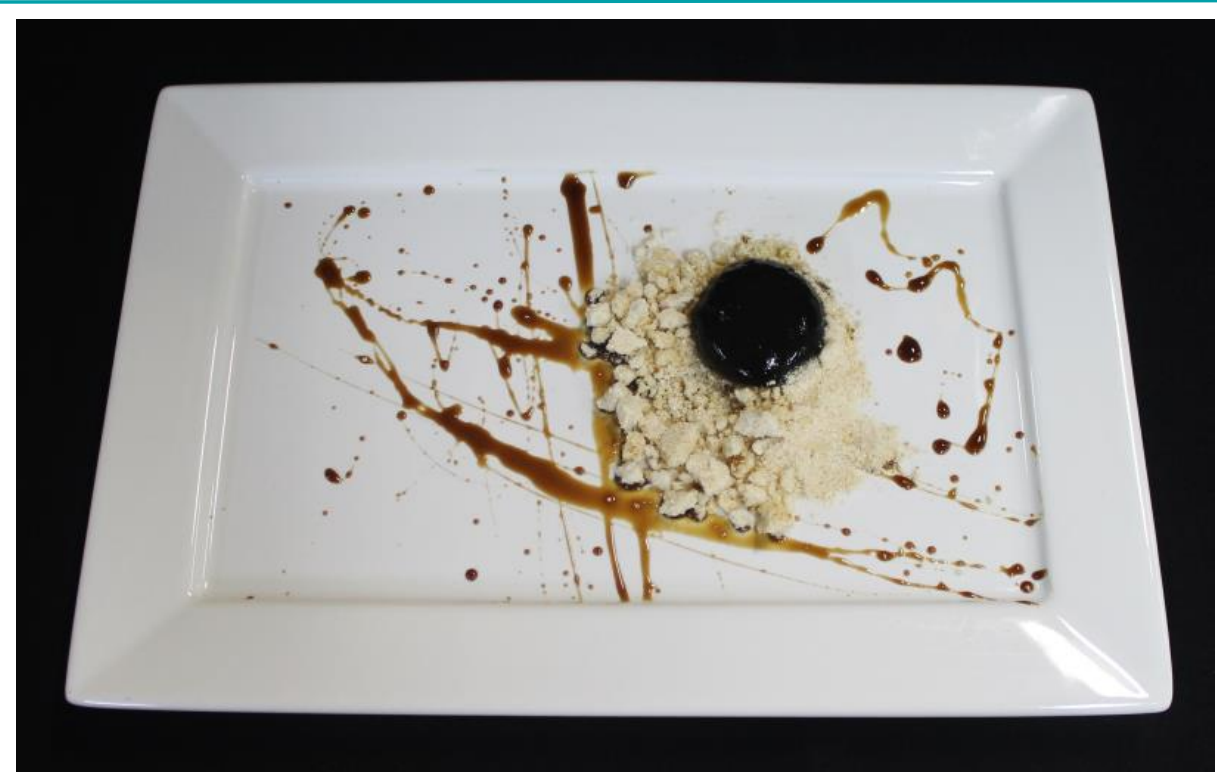

Figura 2. Desconcertante.

Fonte: Autoras, 2017.

O nome da consertada origina-se do café passado, que restava no bule em cima do fogão a lenha, e para aproveitar a sobra, adicionava-se a cachaça e especiarias, resultando-se assim em uma bebida "consertada", para ser oferecida às visitas. O tempo de cozimento também é essencial para definir o sabor. Além disso, a consertada é considerada patrimônio imaterial da cidade de Bombinhas/SC, conforme a lei municipal no 1318/2013.

A utilização do beiju nesta produção remete à herança indígena, bem como à tradição dos descendentes dos açorianos de consumirem esse alimento enquanto tomavam café, muitas vezes acompanhado de melado.

Seu olhar contemporâneo deu-se através de um empratamento contemporâneo da consertada e a utilização de hidrocolóides, como o alginato e o cálcio, para realizar a esferificação inversa da consertada. Priorizou-se o uso da esferificação inversa pela consertada ser o componente principal do prato, além de que o melado foi adicionado depois do primeiro teste para trazer o adocicado que faltava ao prato. A utilização do beiju deu-se por ser constituído de um ingrediente considerado tradicional neste trabalho e por já estar pronto para consumo, precisando somente quebrar em pedaços com um pilão pequeno. A redução de café foi aplicada ao prato com o auxílio de um pincel de silicone.

Após todas as técnicas aplicadas e produções feitas, realizou-se a degustação da sobremesa. Constatou-se que o sabor do café foi enaltecido com a junção da redução do café e da consertada, sendo o sabor da cachaça e das especiarias sentidas ao fundo, o beiju trouxe a crocância e o melado trouxe um sabor doce ao fundo. Quando decomposto a esfera da consertada, a mesma trouxe umidade para o beiju, não deixando a sensação de falta de um componente úmido na sobremesa. Além de que a esfera traz uma nova sensação de consumo ao degustador, onde o mesmo não espera sair um líquido de dentro da esferificação.

As fichas técnicas de produção (tabelas 7 e 8) demonstram os procedimentos e métodos de cocção utilizados na elaboração da sobremesa. 
NOME DO PRODUTO: CONSERTADA

\begin{tabular}{l|l|l}
\hline \multicolumn{1}{c|}{ INGREDIENTE } & \multicolumn{1}{|c}{ QUANTIDADE } & \multicolumn{1}{c}{ UNIDADE } \\
\hline Café forte passado & 500 & $\mathrm{ml}$ \\
Cachaça & 250 & $\mathrm{ml}$ \\
Açúcar mascavo & 50 & $\mathrm{~g}$ \\
Gengibre & 20 & $\mathrm{~g}$ \\
Cravo & 4 & unid \\
Canela em pau & 2 & unid \\
\hline TOTAL & 820 & $\mathrm{~g}$ \\
\hline
\end{tabular}

Modo de preparo:

1. Descasque o gengibre e corte em fatias finas.

2. Em uma panela, junte a cachaça, o açúcar mascavo, o gengibre, o cravo e a canela e leve ao fogo por 10 minutos.

3. Deixe em infusão por 24 horas.

4. Adicione o café na cachaça e leve ao fogo. Quando levantar fervura, desligue.

NOME DO PRODUTO: REDUÇÃO DE CAFÉ

\begin{tabular}{l|l|l}
\hline \multicolumn{1}{c|}{ INGREDIENTE } & \multicolumn{1}{|c}{ QUANTIDADE } & \multicolumn{1}{c}{ UNIDADE } \\
\hline Café forte passado & 250 & $\mathrm{ml}$ \\
Xarope simples & 100 & $\mathrm{ml}$ \\
\hline TOTAL & 350 & $\mathrm{ml}$ \\
\hline
\end{tabular}

Modo de preparo:

1. Em uma panela, junte todos os ingredientes e leve ao fogo por 10 minutos.

Tabela 8. Produção da Redução de café.

Fonte: Autoras, 2017.

\subsection{Sobremesa 3: "Refrescância"}

A terceira sobremesa intitulada como "Refrescância" consiste em uma sopa de jabuticaba "in natura" com crocante de mandioca e casca de jabuticaba desidratada, flores campestres e pérolas de sagu de jabuticaba, conforme consta na figura 3. Os ingredientes destacados neste trabalho que foram utilizados são a jabuticaba, tanto a polpa como a casca na forma desidratada, e a mandioca. 


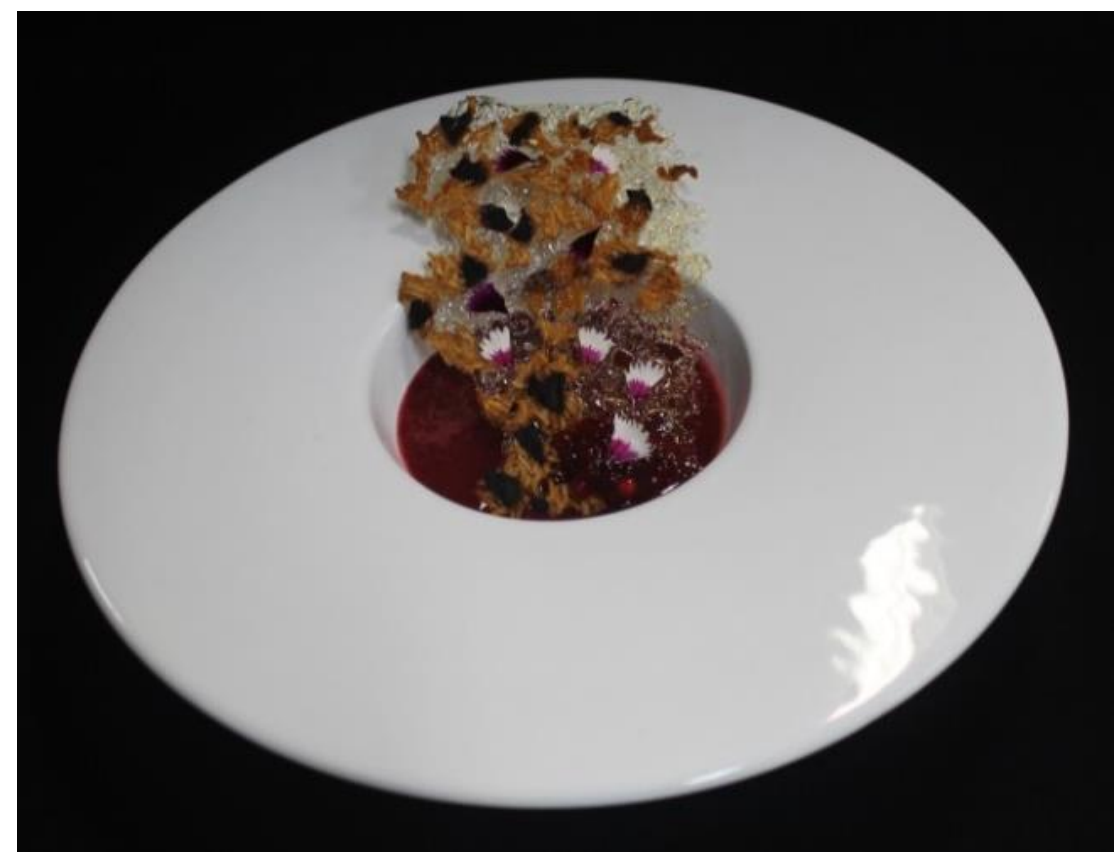

Figura 3. Refrescância.

Fonte: Autoras, 2017.

A escolha pela utilização da jabuticaba coroada foi devido à sua doçura, em comparação com as demais variedades testadas. A jabuticaba utilizada teve o seu teor de sólidos solúveis determinado com auxílio de um refratômetro manual, obtendo um resultado de 13으 Brix, que representa uma fruta em estado ótimo de maturação de acordo com os dados obtidos de Coletti (2012).

Para a extração do suco de jabuticaba, utilizou-se a centrífuga de frutas, sendo esta a melhor técnica para a fruta selecionada, obtendo-se um suco com baixo amargor. Optou-se por utilizar $0,5 \%$ de xantana sobre a quantidade de suco de jabuticaba obtido para atingir a consistência desejada e houve, também, o cuidado com a utilização do mixer, batendo vagarosamente para não produzir muitas bolhas de ar indesejadas.

Utilizou-se as cascas resultantes da jabuticaba, após a extração do seu "suco" obtido após o processo do sous vide, foi realizada sua desidratação por 3 horas e 23 minutos no desidratador, servindo assim para ser usada na confecção do crocante de mandioca. Após realizar um teste com o crocante de mandioca e jabuticaba, foi constatada a falta de um item doce na sua preparação. Por isso, para obter a forma e crocância desejada, utilizou-se a glucose de milho, uma vez que o isomalte não teve o mesmo comportamento e sendo descartada a sua utilização.

As pérolas de sagu foram cozidas no método tradicional (fogão) juntamente com o "suco" de jabuticaba com xarope e licor de jabuticaba obtido com a utilização do vácuo e do sous vide. A utilização do sagu deu-se por ser constituído de um ingrediente considerado tradicional neste trabalho (mandioca) e preparado com a jabuticaba para obter a coloração e o sabor da mesma. Já o licor de jabuticaba utilizado é de produção de Ana Arcaro Bez Batti e obtido conforme os saberes tradicionais da mesma.

Após todas as técnicas aplicadas e produções feitas, realizou-se a degustação da sobremesa. Constatou-se um equilíbrio entre os sabores presentes na sobremesa, sendo a sopa de jabuticaba considerada muito refrescante e leve, ideal para um cardápio de primavera, a 
crocância estava presente no crocante de mandioca com jabuticaba e as pérolas de sagu trazem uma maciez para completar a sobremesa.

As fichas técnicas de produção (tabelas 9 e 10) demonstram os procedimentos e métodos de cocção utilizados na elaboração da sobremesa.

\begin{tabular}{l|l|l}
\hline \multicolumn{3}{c}{ NOME DO PRODUTO: SOPA DE JABUTICABA } \\
\hline \multicolumn{1}{c|}{ INGREDIENTE } & \multicolumn{1}{|c}{ QUANTIDADE } & \multicolumn{1}{c}{ UNIDADE } \\
\hline $\begin{array}{l}\text { Jabuticaba in natura } \\
\text { Xantana }\end{array}$ & 425 & $\mathrm{~g}$ \\
\hline TOTAL & 1,18 & $\mathrm{~g}$ \\
\hline
\end{tabular}

Modo de preparo:

1. Passe a jabuticaba em uma centrífuga de frutas.

2. Adicione a xantana no suco extraído da jabuticaba e bata com um mixer, aos poucos, até a mistura ficar homogênea.

\begin{tabular}{l|l|l}
\hline \multicolumn{2}{c}{ NOME DO PRODUTO: CROCANTE DE MANDIOCA COM JABUTICABA } \\
\hline \multicolumn{1}{c|}{ INGREDIENTE } & \multicolumn{1}{|c}{ QUANTIDADE } & \multicolumn{1}{c}{ UNIDADE } \\
\hline Passo 1: & 678 & $\mathrm{~g}$ \\
Mandioca limpa & 367 & $\mathrm{ml}$ \\
Água & 7 & unid \\
Casca de jabuticaba & & \\
desidratada & & $\mathrm{g}$ \\
Passo 2: & 10 & $\mathrm{~g}$ \\
Mandioca desidratada & 20 & unid \\
Glucose de milho & 2 & $\mathrm{~g}$ \\
Flores silvestres & & \\
\hline TOTAL & 1075 & \\
\hline
\end{tabular}


Modo de preparo:

Passo 1: 1. Passe a mandioca no processador.

2. Em uma panela, junte a mandioca ralada e a água. Leve ao fogo, mexendo sempre, até que a mandioca solte a goma. Desligue o fogo.

3. Espalhe a mandioca em um silpat com o auxílio de uma espátula.

4. Acrescente a casca de jabuticaba picada sobre a mandioca.

5. Leve para o desidratador, a $60^{\circ} \mathrm{C}$ por 12 horas, para secar.

Passo 2: 1. Espalhe a glucose no silpat com o auxílio de uma espátula e acrescente a mandioca desidratada em pedaços irregulares

2. Leve ao forno a $175^{\circ} \mathrm{C}$ até a mandioca ficar dourada.

3. Quando esfriar, acrescente as flores em pedaços.

Tabela 10. Produção do Crocante de mandioca com jabuticaba.

Fonte: Autoras, 2017.

\subsection{Sobremesa 4: “Manezinha”}

A última sobremesa intitulada como "Manezinha" consiste em um bolo de milho com gellée de pitanga, quenelle de coalhada, farofa doce de pinhão, crocante de amendoim, coulis de limão galego e flores campestres (capuchinha e flor de sarraceno), conforme consta na figura 4. Os ingredientes destacados neste produto foram a pitanga, o pinhão, o milho e o amendoim.

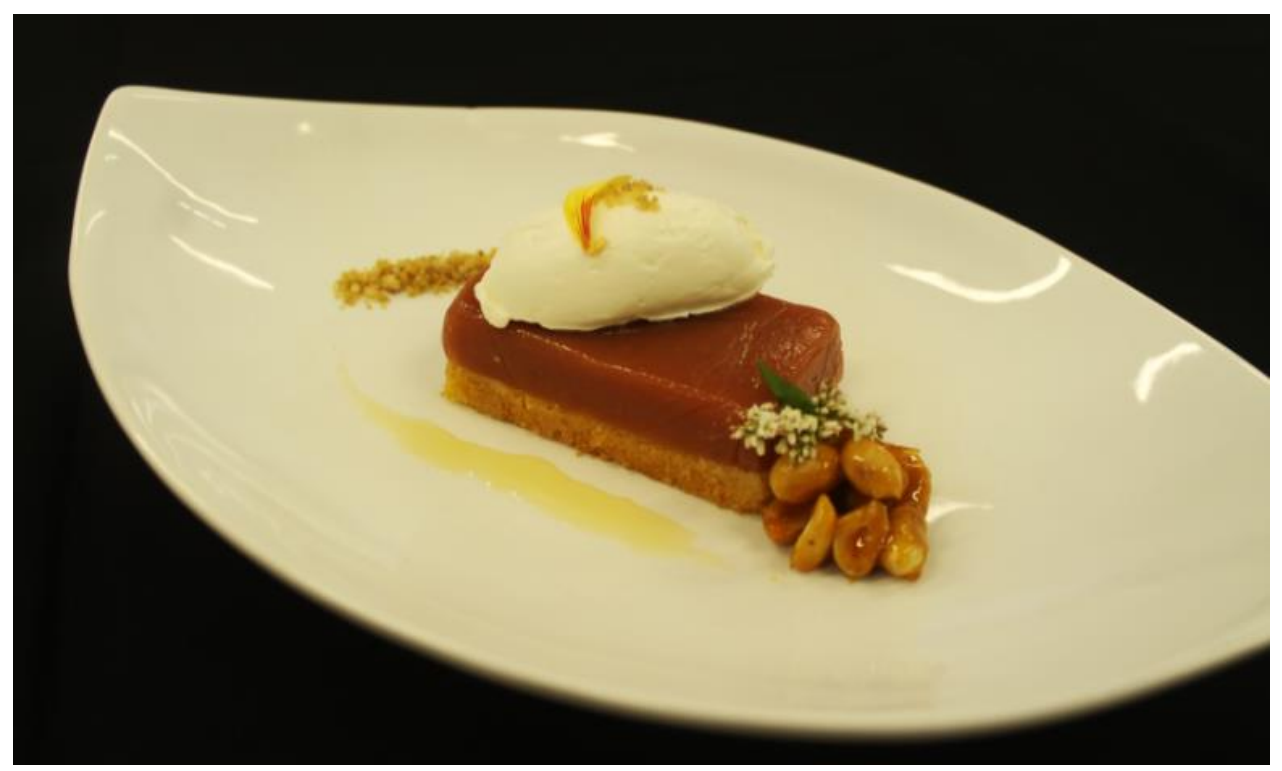

Figura 4. Manezinha.

Fonte: Autoras, 2017.

A pitanga utilizada para a sobremesa possuía 9o Brix, sendo que o teor de sólidos solúveis foi determinado com auxílio de um refratômetro manual portátil e os resultados expressos em oBrix. De acordo com Sanches (2017), os sólidos solúveis designados como ${ }^{\circ}$ Brix tem tendência a aumento com o avanço do amadurecimento do fruto. Assim, a manutenção no teor de sólidos 
solúveis é fundamental para o controle da maturação dos frutos no intuito de retardar o processo de senescência. Desta forma, o resultado encontrado neste trabalho corrobora com Pio et al. (2005, apud DONADIO et al., 2002) em que afirma que os frutos maduros de pitangueira possuem, em média, de 8,3 a $11,6^{\circ}$ Brix.

Utilizou-se a embaladora a vácuo Selovac 200 B para a pitanga e, após alguns testes, para obter o resultado desejado, escolheu-se o programa 3 da máquina, sendo que a mesma possui 9 programas, com 40 segundos de vácuo, tempo de selagem: 1,7 segundos e cap. da bomba Busch de vácuo: $25 \mathrm{~m}^{3} / \mathrm{h}$. Após esse procedimento, fez-se o uso do sous vide na pitanga, sendo que a fruta manteve-se inteira após o processo, enaltecendo ainda mais o brilho, sabor e aroma da fruta. Houve o emprego do hidrocolóide ágar para a obtenção do gellée, sendo utilizado 1\% para obter a consistência desejada.

A escolha pelo bolo de milho ocorreu por ser uma produção tradicional de Florianópolis, um dos doces mais consumidos pelos descendentes dos açorianos. 0 milho, de origem indígena, era cultivado em todos os pontos do município de Florianópolis (Desterro) nas suas três espécies conhecidas - o pipoca (miudinho), o roxo, o amarelo grande ou vermelho grande de acordo com Müller (2012).

Já a coalhada foi utilizada para valorizar e disseminar sua técnica e produto, visto que sua produção advém de pequenos produtores.

Após todas as técnicas aplicadas e produções feitas, realizou-se a degustação da sobremesa. Constatou-se um equilíbrio entre os sabores presentes na sobremesa, o bolo de milho e o gellée de pitanga se complementam, sendo que a pitanga aparece bem ao fundo, a crocância estava presente no amendoim, tanto inserido no crocante como na farofa doce de pinhão, o coulis de limão galego trouxe uma leve acidez e a quenelle de coalhada trouxe a refrescância para complementar a sobremesa.

As fichas técnicas de produção (tabelas 11, 12, 13, 14 e 15) demonstram os procedimentos e métodos de cocção utilizados na elaboração da sobremesa.

\begin{tabular}{l|l|l}
\hline \multicolumn{3}{c}{ NOME DO PRODUTO: GELLÉE DE PITANGA } \\
\hline \multicolumn{1}{c|}{ INGREDIENTE } & \multicolumn{1}{|c}{ QUANTIDADE } & \multicolumn{1}{c}{ UNIDADE } \\
\hline Passo 1: & 285 & $\mathrm{~g}$ \\
Pitanga in natura & 70 & $\mathrm{ml}$ \\
Xarope simples & & \\
Passo 2: & 50 & $\mathrm{ml}$ \\
“Suco" da pitanga 1 & 120 & $\mathrm{ml}$ \\
"Suco" da pitanga 2 & 2 & $\mathrm{~g}$ \\
Ágar & 527 & $\mathrm{~g}$ \\
\hline TOTAL & & \\
\hline
\end{tabular}


Modo de preparo:

Passo 1: 1. Coloque todos os ingredientes no saco plástico específico para usar com a embaladora a vácuo.

2. Leve para a embaladora a vácuo e dê o vácuo por 40 segundos.

3. Leve para a geladeira e deixe por 24 horas.

4. Coloque a pitanga no sous vide a $83^{\circ} \mathrm{C}$ por 30 minutos.

5. Quando esfriar, abra o saco plástico, esprema a pitanga, com o auxílio de uma colher, em uma peneira.

Passo 2: 1. Em uma panela, adicione o "suco" de pitanga 1 e leve ao fogo.

2. Quando levantar fervura, retire do fogo, acrescente o ágar mexendo com um foeut. Retorne ao fogo por 15 segundos.

3. Retire o líquido do fogo e despeje sobre o "suco" de pitanga 2, mexendo com um foeut.

4. Coloque nas forminhas desejadas e leve para geladeira.

NOME DO PRODUTO: BOLO DE MILHO

\begin{tabular}{l|l|l}
\hline \multicolumn{1}{c|}{ INGREDIENTE } & \multicolumn{1}{|c}{ QUANTIDADE } & UNIDADE \\
\hline Milho em conserva (com & 300 & $\mathrm{~g}$ \\
água) & 215 & $\mathrm{~g}$ \\
Óleo de soja & 200 & $\mathrm{~g}$ \\
Açúcar & 150 & $\mathrm{~g}$ \\
Fubá & 150 & $\mathrm{~g}$ \\
Ovos & 40 & $\mathrm{~g}$ \\
Farinha de trigo & 20 & $\mathrm{~g}$ \\
Coco ralado & 25 & $\mathrm{~g}$ \\
Fermento químico & & \\
\hline TOTAL & 1100 & $\mathrm{~g}$ \\
\hline
\end{tabular}

Modo de preparo:

1. Bata o milho, o óleo, o açúcar, o fubá, os ovos a farinha de trigo no liquidificador.

2. Coloque a massa em uma vasilha e acrescente o coco ralado e o fermento químico.

3. Despeja a massa em uma forma untada e enfarinhada.

4. Leve para assar em forno pré-aquecido a 165 으 de 30 a 40 minutos. 


\begin{tabular}{l|l|l}
\hline \multicolumn{3}{c}{ NOME DO PRODUTO: COULIS DE LIMÃO GALEGO } \\
\hline \multicolumn{1}{c|}{ INGREDIENTE } & \multicolumn{1}{|c}{ QUANTIDADE } & \multicolumn{1}{c}{ UNIDADE } \\
\hline $\begin{array}{l}\text { Limão galego } \\
\text { Xarope simples }\end{array}$ & 2 & $\begin{array}{l}\text { unid } \\
\mathrm{ml}\end{array}$ \\
\hline TOTAL & 200 & $\mathrm{~g}$ \\
\hline
\end{tabular}

Modo de preparo:

1. Retire o suco dos limões e coe.

2. Em uma panela, junte o suco e o xarope.

3. Leve ao fogo até obter a consistência desejada.

\begin{tabular}{l|l|l}
\hline \multicolumn{3}{c}{ NOME DO PRODUTO: CROCANTE DE AMENDOIM } \\
\hline \multicolumn{1}{c|}{ INGREDIENTE } & \multicolumn{1}{c}{ QUANTIDADE } & \multicolumn{1}{c}{ UNIDADE } \\
\hline Amendoim & 100 & $\mathrm{~g}$ \\
Açúcar & 150 & $\mathrm{~g}$ \\
\hline TOTAL & 250 & $\mathrm{~g}$ \\
\hline
\end{tabular}

Modo de preparo:

1. Torre o amendoim no forno e retire a casca. Reserve.

2. Em uma panela, adicione o açúcar e leve ao fogo.

3. Quando o açúcar caramelizar, adicione o amendoim e mexa para incorporar os ingredientes.

4. Desligue o fogo e espalhe o amendoim em um silpat.

5. Quando esfriar, quebre o crocante de amendoim no tamanho desejado. 


\begin{tabular}{l|l|l}
\hline \multicolumn{3}{c}{ NOME DO PRODUTO: FAROFA DOCE DE PINHÃO } \\
\hline \multicolumn{1}{c|}{ INGREDIENTE } & \multicolumn{1}{|c}{ QUANTIDADE } & \multicolumn{1}{c}{ UNIDADE } \\
\hline Paçoca de pinhão & 230 & $\mathrm{~g}$ \\
Amendoim & 200 & $\mathrm{~g}$ \\
Açúcar mascavo & 200 & $\mathrm{~g}$ \\
Fubá & 200 & $\mathrm{~g}$ \\
\hline TOTAL & 830 & $\mathrm{~g}$ \\
\hline
\end{tabular}

Modo de preparo:

1. Torre o amendoim no forno e retire a casca.

2. Junte todos os ingredientes e leve ao processador até a mistura ficar homogênea.

Tabela 15. Produção da Farofa doce de pinhão.

Fonte: Autoras, 2017.

\section{CONCLUSÃO}

O trabalho teve como principal objetivo a valorização dos atributos sensoriais dos produtos regionais presentes na biodiversidade brasileira e dos saberes e fazeres culinários catarinenses, utilizando técnicas de preparo contemporâneas que ampliem o desenvolvimento de sobremesas no ambiente de restauração. O objetivo foi alcançado devido à utilização da metodologia de Processo de Desenvolvimento de Produto, que permite a criação de critérios específicos para a elaboração das sobremesas desenvolvidas, bem como a utilização dos processos e ingredientes contemporâneos empregados.

O poder que a gastronomia possui em manter vivo o patrimônio cultural é um dos aspectos de sua sustentabilidade, sendo que sua função torna-se mais do que simplesmente nutrir o ser humano. Além disso, elaborar um cardápio com ingredientes locais e sazonais é estar conectado, não somente com as novas tendências gastronômicas, mas também com um método racional e sensível de usar os recursos disponíveis pela natureza.

A diminuição da utilização de ingredientes locais na gastronomia tradicional ou no desenvolvimento de novas receitas pode levar ao desaparecimento de um ingrediente pelo seu desuso e a padronização de uma cultura gastronômica local (AMARAL, 2016).

As sobremesas contemporâneas desenvolvidas "Dona Bijajica, Desconcertante, Refrescância e Manezinha" afirmam a possibilidade de utilizar os saberes e fazeres tradicionais de Santa Catarina mesclando com as frutas típicas brasileiras em diferentes produções gastronômicas e mostram que as técnicas de cozinha contemporâneas podem valorizar ingredientes locais com pouco uso na cozinha.

Como sugestões para futuras pesquisas indicam-se a possibilidade de utilização de outras frutas típicas brasileiras e de outras estações do ano, levantamento do custo de produção das sobremesas, bem como seu preço de venda, a utilização de outros hidrocolóides e ampliação da apropriação gastronômica de outros saberes e fazeres tradicionais. 


\section{REFERÊNCIAS}

ALIJA, Josean, TALENS, Clara. New concept of desserts with no added sugar. Tradução de Érika Arcaro Bez Batti. International Journal of Gastronomy and Food Science, Spain, v. 1, p. 116-122, 2012.

AMARAL, Fabiana Mortimer. Desenvolvimento de produções gastronômicas salgadas com gila (Cucurbita ficifolia): uma alternativa para valorização e promoção do produto local. Turismo, gastronomia e desenvolvimento na região das Missões - Brasil, Santo Ângelo, v. 1, p. 203-220, 2016.

ARCA do gosto. Slow Food, [s.I.], jul. 2007. Seção Arca do Gosto. Disponível em: <http://www.slowfoodbrasil.com/arca-do-gosto>. Acesso em: 22 set. 2017.

BALDWIN, Douglas. Sous vide cooking: A review. Tradução de Érika Arcaro Bez Batti. International Journal of Gastronomy and Food Science, United States, v. 1, p. 15-30, 2012.

BIJAJICA. Slow Food, [s.I.], jun. 2014. Seção Arca do Gosto. Disponível em: <https://www.slowfoodbrasil.com/arca-dogosto/produtos-do-brasil/762-bijajica>. Acesso em: 22 set. 2017.

CANELLA-RAWLS, Sandra. Espessantes na confeitaria: texturas e sabores. São Paulo: Senac São Paulo, 2014.

COLETTI, Luana Yoneda. Curva de maturação de frutos e potencial germinativo de sementes de jabuticaba 'Sabará' (Myrciaria jaboticaba Berg). 2012. 60 f. Dissertação (mestrado em Ciências), Universidade de São Paulo, Piracicaba, 2012.

CUNHA, Agnes Damaris de Melo et al. Releitura de sobremesa: do clássico para o contemporâneo. Famesp, [s.I.], 2014. Disponível em: <http://famesp.com.br/novosite/wpcontent/uploads/2014/tcc/famesp agnes damaris de melo cunha.pdf.>. Acesso em: 15 ago. 2017.

FARIA, Adriana Ferreira de Faria et al. Processo de desenvolvimento de novos produtos: uma experiência didática. Abepro, Rio de Janeiro, out. 2008. Disponível em: <http://www.abepro.org.br/biblioteca/enegep2008 TN STP 073521 12155.pdf>. Acesso em: 07 ago. 2017.

FARIAS, Luiz. Padaria Brasil: o modelo da padaria e confeitaria brasileira. Tradução de Lucimara S. Braga Muniz, Esther Jiménez Vives; Revisão de Israel Eusébio Lopez. São Paulo: LMA Editora, 2013.

FERREIRA, Paola Biselli. O doce brasileiro como identidade cultural. In: CONGRESSO INTERNACIONAL DE GASTRONOMIA, 2013. São Paulo. Anais... Mesa Tendências 2013. São Paulo: Centro Universitário Senac, 2013. p. 01389.

FERREIRA, Márcia; DIAS, Marília. Consertada, pratimônio imaterial bombinense. Fundação municipal de cultura de Bombinhas/SC, Bombinhas, 2017. Disponível em: <http://www.culturabombinhas.com.br/p/consertada.html>. Acesso em: 10 dez. 2017.

FORTALEZA do pinhão da serra catarinense. Slow Food, [s.I.], jul. 2008. Seção Arca do Gosto. Disponível em: <http://www.slowfoodbrasil.com/fortalezas/fortalezas-no-brasil/231-fortaleza-do-pinhao-da-serra-catarinense>. Acesso em: 22 set. 2017.

HERMÉ, Pierre. Larousse das sobremesas. São Paulo: Larousse do Brasil, 2005.

KRAUSE, Rodolfo, BAHLS, Álvaro. Orientações gerais para uma gastronomia sustentável. Revista Turismo Visão e Ação - Eletrônica, Balneário Camboriú, v. 15, n. 3, p. 434-450, set/dez 2013.

LORENZI, Harri. Frutas no Brasil: nativas e exóticas (de consumo in natura). Nova Odessa, SP: Instituto Plantarum de Estudos da Flora, 2015.

MEDEIROS, Dalila Loreny. Pesquisa sobre a técnica de sous vide. 2009. 39 f. Monografia (Especialização em Qualidade em Alimentos), Universidade de Brasília, Brasília, 2009. 
MENEGALE, Alexandre. Uma doce história do Brasil. Sabor do Brasil, n. 13, p. 52-59, 2004.

MEZAROBA, Maria Elizabeth de Paula Cançado et al. Predição da vida útil de filés de peito de frango resfriados embalados a vácuo e com atmosfera modificada em condições de armazenamento não isotérmico. B.CEPPA, Curitiba, v. 33, n. 1, p. 79-86, jan./jun. 2015.

MÜLLER, Silvana Graudenz. Patrimônio cultural gastronômico: identificação, sistematização e disseminação dos saberes e fazeres tradicionais. Florianópolis, 2012. 288 p. Tese (Doutorado) - Universidade Federal de Santa Catarina, Centro Tecnológico. Programa de Pós-Graduação em Engenharia e Gestão do Conhecimento.

NAVARRO, Virginia et al. Cooking and nutritional science: Gastronomy goes further. Tradução de Érika Arcaro Bez Batti. International Journal of Gastronomy and Food Science, Spain, v. 1, p. 37-45, 2012.

NUNES, Priscila Barbosa Bezerra, ZEGARRA, Makarenna Del Carmen Chaves Portugal. Sobremesas: de Portugal a Pernambuco. Revista Sorveteria Confeitaria Brasileira, n. 223, p. 10-17, 2016.

ONU cria Dia da Gastronomia Sustentável. ONU BR, [s.I.], dez. 2016. Desenvolvimento Sustentável. Disponível em: <https://nacoesunidas.org/onu-cria-dia-da-gastronomia-sustentavel/>. Acesso em: 06 nov. 2017.

PACHER, Andréia Maria. 0 processo do ensino da confeitaria clássica nas disciplinas de confeitaria, nos cursos superiores de gastronomia em Santa Catarina. 2014. 131 f. Dissertação (mestrado em Turismo e Hotelaria), Universidade do Vale do Itajaí, Balneário Camboriú, 2014.

PEREIRA, Nereu do Vale. Os engenhos de farinha de mandioca da llha de Santa Catarina: etnografia catarinense. Florianópolis: Ed. Fundação Cultural Açoriana, 1993.

PIO, Rafael et al. Características físico-químicas de frutos de pitangueira em função da altura de inserção na planta. Revista Brasileira de Agrociência, Pelotas, v. 11, n. 1, p. 105-107, jan./mar. 2005.

PITANGA. Slow Food, [s.I.], out. 2016. Seção Arca do Gosto. Disponível em: <http://slowfoodbrasil.com/arca-dogosto/produtos-do-brasil/1133-pitanga>. Acesso em: 22 set. 2017.

RAMOS, Ana Elisa Aguiar. O sistema Sous Vide. 2004. 25 f. Monografia (Especialização) - Universidade de Brasília, Centro de Excelência em Turismo, 2004.

SANCHES, Alex Guimarães et al. Qualidade e resistência pós-colheita de jabuticabas tratadas com ácido salicílico. Acta Iguazu, Cascavel, v.4, n.4, p. 28-40, 2015.

SANCHES, Alex Guimarães et al. Tratamentos químicos na manutenção da qualidade pós-colheita em frutos de pitanga (Eugenia uniflora L.). Nativa, Sinop, v. 5, n. 4, p. 257-262, jul./ago. 2017.

SANTOS, Carlos Roberto Antunes. A alimentação e seu lugar na história: os tempos da memória gustativa. História: Questões \& Debates, Curitiba, n. 42, p. 11-31, 2005.

SCHELIGA, Paola Biselli Ferreira. A doçaria paulista no início do século XX. 2016. 71 f. Dissertação (mestrado em Educação, Arte e História da Cultura), Universidade Presbiteriana Mackenzie, São Paulo, 2016.

SCHIOCHET, Flávia. Confeitaria brasileira une Europa e ingredientes locais. Gazeta do Povo, [s.I.], mai. 2016. Secão Bom Gourmet. Disponível em: <http://www.gazetadopovo.com.br/bomgourmet/confeitaria-brasileira-une-doceseuropeus-e-ingredientes-locais/>. Acesso em: 07 ago. 2017

SCHMITZ, Fabíola Zimmermann. Substituição do amido de milho por goma xantana na preparação de cremes de pasteleiro: impacto nas componentes de aroma e textura. 2014. 144 f. Dissertação (mestrado em Ciências Gastronômicas), Faculdade de Ciência e Tecnologia, Lisboa, 2014.

SCHMITZ, Fabíola Zimmermann. Gastronomia Molecular. Florianópolis, 2015. (Apostila de Gastronomia).

SOUTHGATE, Alice Novaes Nogueira. Sobremesas empratadas. Florianópolis, 2015. (Apostila de Confeitaria Contemporânea). 
TRAJANO, Ana Luiza. Cardápios do Brasil: receitas, ingredientes, processos. São Paulo: Senac São Paulo, 2013.

UNITED NATIONS. Resolution Sustainable Gastronomy Day. Resolução n. 71, de 22 de novembro 2016. Disponível em: <http://www.un.org/ga/search/view doc.asp?symbol=A/C.2/71/L.28/Rev.1\&referer=/english/\&Lang=E>. Acesso em: 08 nov. 2017.

VIEITES, Rogério Lopes et al. Caracterização físico-química, bioquímica e funcional da jabuticaba armazenada sob diferentes temperaturas. Revista Brasileira de Fruticultura, Jaboticabal, v. 33, n. 2, p. 362-375, jun. 2011.

VIZZOTTO, Márcia. Fitoquímicos em pitanga (Eugenia uniflora L.): seu potencial na prevenção e combate a doenças. In: II Encontro sobre pequenas frutas e frutas nativas do Mercosul. Pelotas: Embrapa, 2006. p.29-34. 